PREPARED FOR THE U.S. DEPARTMENT OF ENERGY, UNDER CONTRACT DE-AC02-76CH03073

PPPL-3754

PPPL-3754

UC-70

Measurements of Prompt and MHD-induced Fast lon Loss from National Spherical Torus Experiment Plasmas

by

D.S. Darrow, S.S. Medley, A.L. Roquemore, W.W. Heidbrink, A. Alekseyev, F.E. Cecil, J. Egedal, V.Ya. Goloborod'ko, N.N. Gorelenkov, M. Isobe,

S. Kaye, M. Miah, F. Paoletti, M.H. Redi, S.N. Reznik, A. Rosenberg, R. White, D. Wyatt, and V.A Yavorskij

October 2002
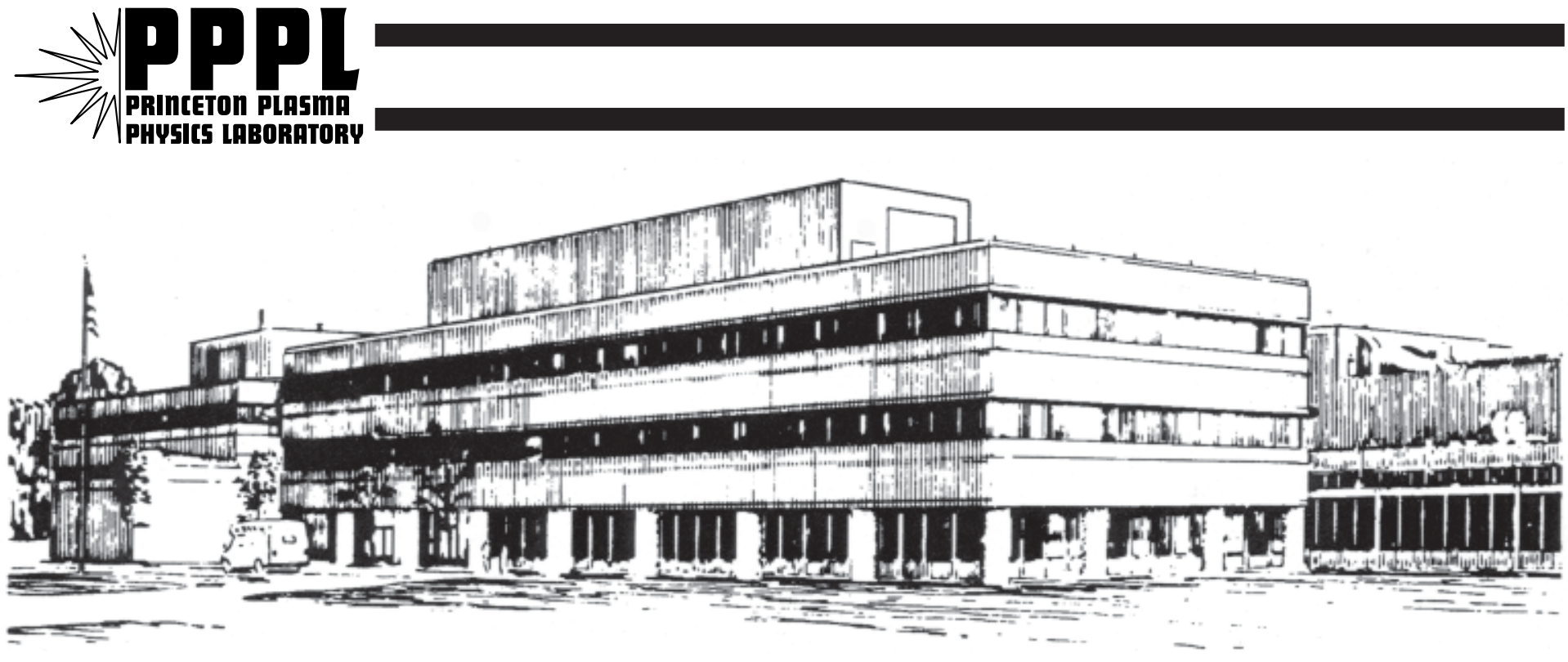

PRINCETON PLASMA PHYSICS LABORATORY PRINCETON UNIVERSITY, PRINCETON, NEW JERSEY 


\section{PPPL Reports Disclaimer}

This report was prepared as an account of work sponsored by an agency of the United States Government. Neither the United States Government nor any agency thereof, nor any of their employees, makes any warranty, express or implied, or assumes any legal liability or responsibility for the accuracy, completeness, or usefulness of any information, apparatus, product, or process disclosed, or represents that its use would not infringe privately owned rights. Reference herein to any specific commercial product, process, or service by trade name, trademark, manufacturer, or otherwise, does not necessarily constitute or imply its endorsement, recommendation, or favoring by the United States Government or any agency thereof. The views and opinions of authors expressed herein do not necessarily state or reflect those of the United States Government or any agency thereof.

\section{Availability}

This report is posted on the U.S. Department of Energy's Princeton Plasma Physics Laboratory Publications and Reports web site in Fiscal Year 2003. The home page for PPPL Reports and Publications is: http://www.pppl.gov/pub_report/

DOE and DOE Contractors can obtain copies of this report from:

U.S. Department of Energy

Office of Scientific and Technical Information

DOE Technical Information Services (DTIS)

P.O. Box 62

Oak Ridge, TN 37831

Telephone: (865) 576-8401

Fax: (865) 576-5728

Email: reports@adonis.osti.gov

This report is available to the general public from:

National Technical Information Service

U.S. Department of Commerce

5285 Port Royal Road

Springfield, VA 22161

Telephone: $1-800-553-6847$ or

(703) $605-6000$

Fax: (703) 321-8547

Internet: http://www.ntis.gov/ordering.htm 


\title{
Measurements of Prompt and MHD-Induced Fast Ion Loss from National Spherical Torus Experiment Plasmas
}

D. S. Darrow 1), S. S. Medley 1), A. L. Roquemore 1), W. W. Heidbrink 2), A. Alekseyev 3), F. E. Cecil 4), J. Egedal 5), V.Ya.Goloborod'ko 6), N. N. Gorelenkov 1), M. Isobe 7), S. Kaye 1), M. Miah 2), F. Paoletti 8), M. H. Redi 1), S.N.Reznik 6), A. Rosenberg 1), R. White 1), D. Wyatt 9), V. A. Yavorskij 6)

1) Princeton Plasma Physics Laboratory, Princeton, NJ, USA

2) University of California, Irvine, CA, USA

3) TRINITI, Troitsk, Moscow Region, Russia

4) Colorado School of Mines, Golden, CO, USA

5) MIT, Cambridge, MA, USA

6) Kyiv Institute for Nuclear Research, Kyiv, Ukraine

7) NIFS, Toki, Japan

8) Columbia University, New York, NY, USA

9) Cornell University, Ithaca, NY, USA

email contact of main author: ddarrow@pppl.gov

\begin{abstract}
A range of effects may make fast ion confinement in spherical tokamaks worse than in conventional aspect ratio tokamaks. Data from neutron detectors, a neutral particle analyzer, and a fast ion loss diagnostic on the National Spherical Torus Experiment (NSTX) indicate that neutral beam ion confinement is consistent with classical expectations in quiescent plasmas, within the $\sim 25 \%$ errors of measurement. However, fast ion confinement in NSTX is frequently affected by magnetohydrodynamic (MHD) activity, and the effect of MHD can be quite strong.
\end{abstract}

\section{Introduction}

Spherical tokamaks (STs) operate at significantly lower magnetic field than do most tokamaks at ordinary aspect ratios, e.g. $\mathrm{B}_{\mathrm{T}}=0.3 \mathrm{~T}$ in NSTX compared to $2-5 \mathrm{~T}$ in similarlysized conventional tokamaks. As a consequence, the gyroradii of fast ions (e.g. neutral beam (NB) ions, ion cyclotron heated tail ions, and charged fusion products) can be a significant fraction of the plasma minor radius, contributing to possible degraded confinement of these ions. In this work, we examine diagnostic data from NSTX $\left(B_{T}=0.3-0.6 \mathrm{~T}, \mathrm{I}_{\mathrm{p}} \sim 1 \mathrm{MA}\right.$, $\mathrm{n}_{\mathrm{e}} \sim 2-8 \times 10^{19} \mathrm{~m}^{-3}, \mathrm{~T}_{\mathrm{e}} \sim \mathrm{T}_{\mathrm{i}} \sim 600-1000 \mathrm{eV}$ ) to determine whether NB ion confinement departs from classical expectations in quiescent plasmas. In addition, we describe some observed effects of MHD activity on the fast ion diagnostic signals.

\section{Implications of low B on fast ion confinement}

As noted above, the relatively low magnetic field strength in STs means that fast ions will have large gyroradii. For example, the $80 \mathrm{keV}$ D (co-injected) NB heating ions in NSTX can have a gyroradius of $\sim 0.3 \mathrm{~m}$ at the outboard midplane of the plasma. This is a sizable fraction of the $0.68 \mathrm{~m}$ minor radius of a typical plasma. Additional prompt loss to the walls from the large gyroradius is therefore expected and seen in numerical simulations.[1] The large fast ion gyroradius in an ST also can be comparable to the gradient scale length of the magnetic field, meaning that the fast ion magnetic moment $(\mu)$ may not be well conserved. If $\mu$ invariance is broken, then it is possible that orbit stochasticity can cause fast ions to be lost. Indeed, stochasticity in NB ion orbits in NSTX has been observed in orbit modeling, due to resonant interaction between gyromotion and bounce motion.[2] However, other theoretical work[3] 
indicates that the net effect of the loss of invariance is quite small, apparently because another invariant arises.[2]

The large gyroradius of fast ions in STs can also augment MHD-induced loss because a smaller radial displacement is required in an ST to bring a fast ion orbit from the plasma interior to the point where it can intersect the wall. Finally, the low magnetic field means that fast ions can easily be present at velocities above the Alfvén velocity, possibly driving Alfvén-type instabilities.[4] These could then cause expulsion of the fast ions

\section{Beam blip measurements}

The deviation of fast ion behavior from classical was investigated by analyzing neutron emission resulting from short ( $3 \mathrm{~ms}$ ) beam pulses ("blips") injected into NSTX plasmas. This method[5] provides two measurements of possible losses of neutral beam ions. First, the absolute height of the resulting neutron pulse can be compared to the rate expected from the beam injection power and the plasma density to obtain a measure of the loss fraction of the beam ions arising from short time scale $(<3 \mathrm{~ms})$ processes, typically prompt loss. Second, the decay constant of the neutron rate vs time after the beam blip ends can be compared with the decay rate expected due to collisional slowing down of the beam ions. Any faster than classical decay indicates an additional loss mechanism is operative on a time scale comparable to the slowing down time (typically a few tens of milliseconds).

Beam blip measurements were made in plasmas with $0.5 \mathrm{MA} \leq \mathrm{I}_{\mathrm{p}} \leq 1.0 \mathrm{MA}$ and $0.25 \mathrm{~T} \leq \mathrm{B}_{\mathrm{T}}$ $\leq 0.55 \mathrm{~T}$, with each of the three NSTX NB sources (tangency radii of $0.487,0.592$, and 0.694 $\mathrm{m})$. The data exhibited the expected variation in loss fraction with current and with beam tangency radius, the two variables which most strongly influence prompt loss. There was, however, significant scatter, amounting to $+/-25 \%$ in some cases. When the ratio of measured peak neutron rate to the rate computed by the TRANSP[6] transport code is plotted as a function of plasma current, the data show no systematic dependence on plasma current. This indicates that the prompt losses are purely orbit loss as this is the dominant fast ion loss mechanism in TRANSP under these conditions. In some cases, excellent agreement between

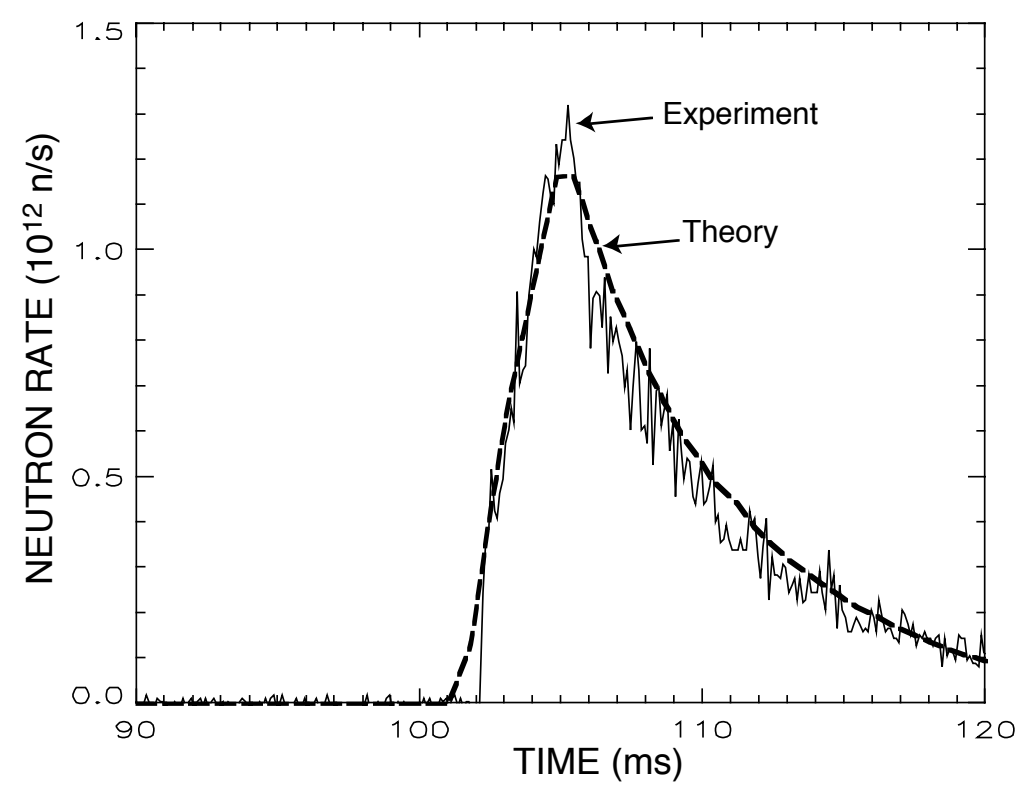

FIG. 1: Measured and modeled neutron rate vs time for an NSTX beam blip. the measured neutron rate and the calculated neutron rate is observed (Fig. 1).

The ratio of measured neutron decay time to that computed by TRANSP was also plotted as a function of plasma current and toroidal field. The ratios are scattered uniformly about a ratio of 1 , with a standard deviation of $\sim 0.25$. This implies that the slower time scale losses are also strictly classical. The data taken as the toroidal field varied set a limit on the loss rate that may be present due to non-conservation of , namely that it is no larger than the $25 \%$ scatter cited 
above. The amount of scatter in both the neutron pulse amplitude and decay time is larger than anticipated and is present in spite of removal of shots with obvious MHD activity from the data set. We conjecture that the scatter may be attributable to low level MHD activity.

\section{Loss measurements}

Losses of ions with energy $>1 \mathrm{keV}$ in NSTX have been measured with a Faraday cup probe located at the vessel midplane. These can be compared with a numerical model of prompt orbit loss from NSTX plasmas. However, because the numerical model does not yet take into account some effects of the beam deposition profile, only general conclusions may be drawn from the comparisons. Except during MHD activity, observed losses are at or below the rate predicted by the model, indicating that there are no large non-classical loss processes active.

\section{NPA data}

NSTX is equipped with a neutral particle energy analyzer (NPA) capable of looking at neutrals with tens of $\mathrm{keV}$ of energy. The NPA line of sight can be scanned in the midplane from tangency radii up to $1.28 \mathrm{~m}$ for co-going particles and $0.75 \mathrm{~m}$ for counter-going particles. With the NPA viewing co-going particles at a tangency radius of $0.70 \mathrm{~m}$, the time evolution of the fast neutral energy spectrum was observed over the course of NB injection in a quiescent shot, 106099. The energy spectrum evolved with time, but reached a steady distribution after $\sim 25 \mathrm{~ms}$. For the parameters of this plasma, the interval required for equilibration, calculated from the collisional slowing down time, was $23 \mathrm{~ms}$, meaning that the

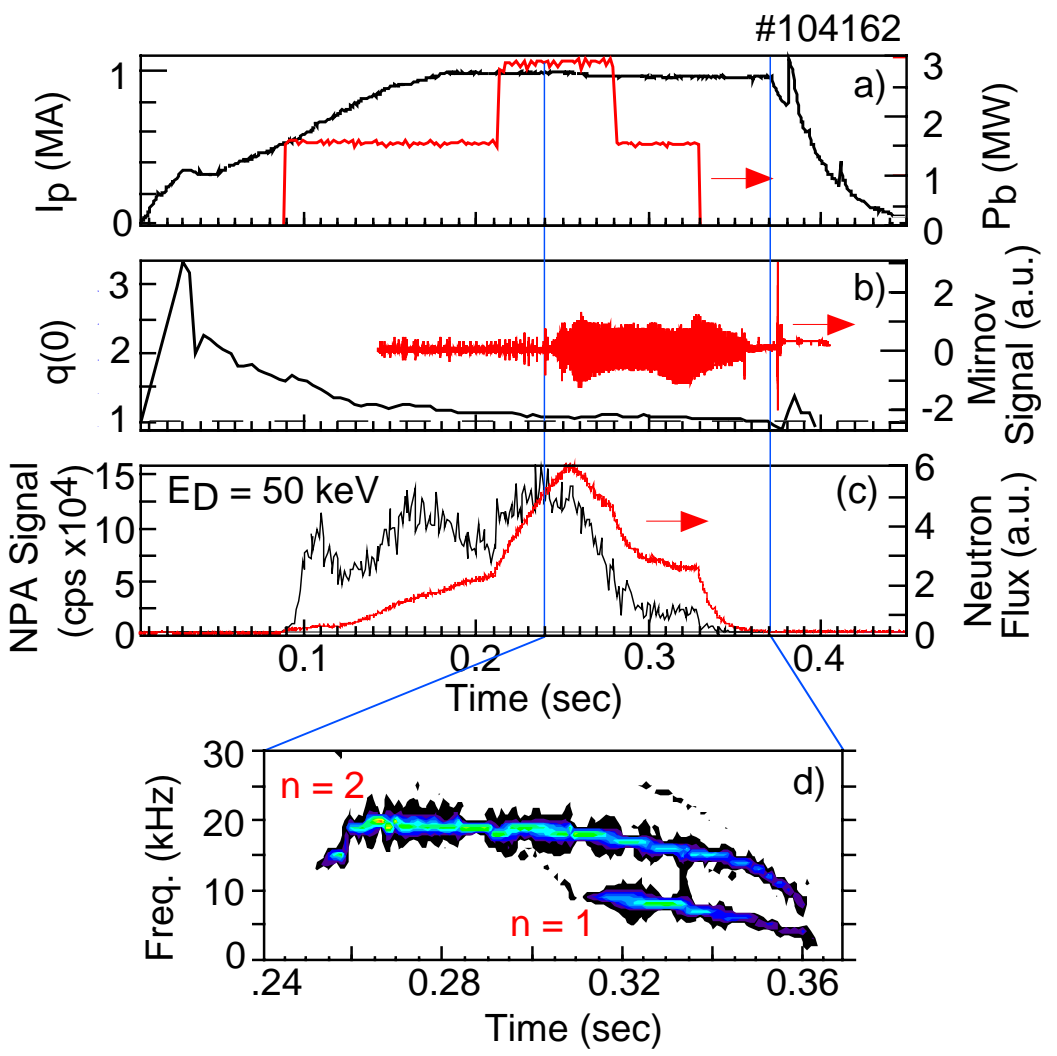

FIG. 2: Influence of MHD activity on beam ion confinement in NSTX. (a) Plamsa current and neutral beam power. (b) Central $q$ value and Mirnov coil signal. (c) $50 \mathrm{keV}$ neutral D efflux and neutron emission. (d) Mirnov spectrogram. observed equilibration time was consistent with classical collisional processes.

Similarly, the rate of collisional pitch angle scattering was assessed by setting the NPA to view the plasma near perpendicularly (tangency radius of $0.15 \mathrm{~m}$ ) during a set of beam injected plasmas. It was seen that the population of perpendicular particles at and below the critical energy $(\sim 15 \mathrm{keV})$ was initially empty. It increased to reach a steady value on the time scale of $\sim 50 \mathrm{~ms}$, in good agreement with the computed pitch angle scattering time of $56 \mathrm{~ms}$ for that condition. So, in both these examples and 
many similar discharges, the NB ion behavior inside the plasma appears consistent with classical collisional processes.

\section{MHD effects on beam ion confinement}

MHD activity can have a strong effect on the fast ion population in NSTX, as shown in Fig. 2. In this discharge, an $\mathrm{n}=2$ mode at $\sim 20 \mathrm{kHz}$ becomes prominent at $0.26 \mathrm{~s}$, joined by an $\mathrm{n}=1$ mode at $\sim 10 \mathrm{kHz}$ at $0.31 \mathrm{~s}$. Note that $\mathrm{q}_{0}$ remains above unity throughout the MHD activity. Simultaneous with the development of the $n=2$ mode, the neutron and energetic neutral flux begin to diminish gradually. At the point just before one of the neutral beams switches off, at $0.28 \mathrm{~s}$, the neutron rate has diminished by $\sim 25 \%$, and the fast neutral flux has diminished by $\sim 50 \%$. In the interval where the neutron rate declines, $\mathrm{n}_{\mathrm{e}}$ and $\mathrm{T}_{\mathrm{e}}$ continue to rise, indicating that the diminishing neutron rate arises from degraded beam ion confinement, not degraded plasma conditions.

In contrast with the MHD mode in the case above, sawteeth and reconnection events in NSTX cause very rapid loss of beam ions in less than $2 \mathrm{~ms}$. Figure 3 shows an example of this. Reconnection events are characterized by sudden upward spikes in both the plasma current trace and $\mathrm{q}_{0}$ and are delineated by solid vertical lines in Fig. 3. These are preceded by two

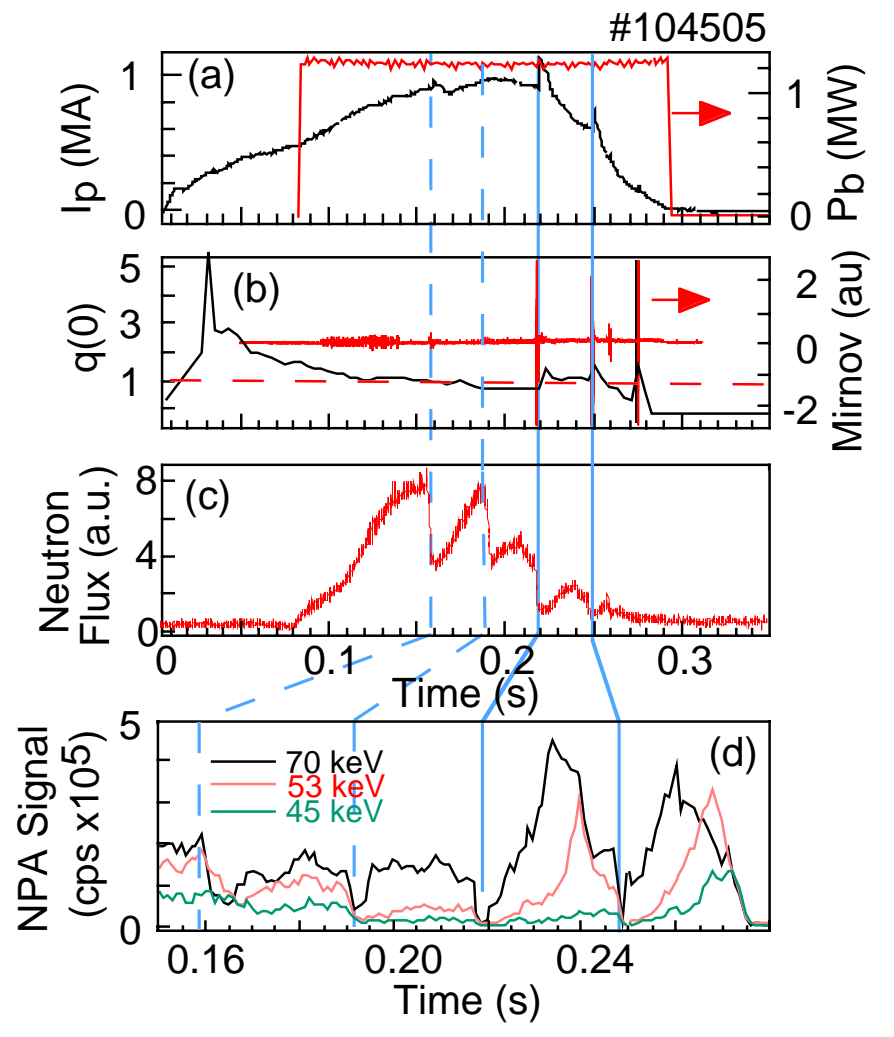

FIG. 3: Influence of sawteeth and reconnection events on beam ion confinement in NSTX. (a) Plasma current and neutral beam power. (b) q0 and Mirnov coil signal. (c) Neutron rate. (d) Neutral D efflux at 70, 53, \& $45 \mathrm{keV}$. The first two events, marked by dashed vertical lines, are sawteeth, and the latter two, marked by solid lines, are reconnection events. sawteeth or other events at earlier times, marked by dashed vertical lines. Simultaneous with the reconnection events are brief spikes in the Mirnov coil signal, which contrast with the steady Mirnov activity in Fig. 2. As Fig. 3 shows, sawteeth and reconnection events cause rapid depletion of the fast neutral flux over a range of energies, resulting in $\sim 50 \%$ drops in the neutron rate. Because beam injection continues after the events in this discharge, the neutral flux and neutron rate do recover. In other discharges, the neutron rate never recovers to more than about half its initial value. This lack of recovery is not understood, but may result from decreased plasma density and impurity influx induced by the event. The volume within the $\mathrm{q}=1$ surface is a significant fraction of the plasma volume, and the reconnection events probably generate magnetic field stochasticity over that whole volume, affecting a large fraction of the beam ions in the plasma.

In reviewing the neutron signals from all NSTX NB plasmas, it has been 
noted that a large fraction of them show some evidence of an MHD-related effect on the neutron rate. In particular, in a data set of $\sim 400$ NB shots from the 2002 experimental campaign, $\sim 90 \%$ exhibited some degradation of the neutron rate, most frequently from bursting $\mathrm{n}=1,2$, or 3 modes that are probably fishbone modes (see next section).

\section{Observations of fast ion driven MHD}

Several MHD instabilities driven by the NB ions have been identified in NSTX plasmas: compressional Alfvén eigenmodes (CAEs)[7,8], toroidicity-induced Alfvén eigenmodes (TAEs)[9], and fishbones.[10] Of these, the CAEs have no discernable effect on the neutron rate or beam ion loss rate. In some cases, the TAEs cause transient neutron drops of $\leq 10 \%$. The fishbones, however, can have a noticeable effect on the neutron rate, causing it to drop by $25 \%$ in the worst cases. Further study of the TAEs and fishbone modes is warranted to understand their global effect on the discharge.

\section{Summary}

We have examined data from the NSTX neutron monitors, NPA, and fast ion loss probe to assess the degree to which the loss rate of neutral beam ions from NSTX plasmas conforms to classical losses and collisional slowing down and pitch angle scattering. Beam blip experiments indicate that beam ion confinement is in reasonable agreement with the prompt orbit loss model. However, the scatter in the data is $\sim 25 \%$ and mechanisms producing loss at that level or smaller might not be evident. NPA data also indicates that the beam ions are slowing down and pitch angle scattering at the classically-expected collisional rates. However, we have found that $\sim 90 \%$ of NSTX discharges show some evidence of MHD effect on the neutron rate. In many cases, the effect on the neutron rate and the NPA signals are strong, indicating that MHD activity is can have a strong adverse effect on fast ion confinement. These observations suggest that attention must be paid to MHD suppression and control in STs if they are to be heated by fast ions and used for neutron sources or fusion reactors.

\section{Acknowledgements}

This work was supported by US DoE contract number DE-AC02-76CH03073.

\section{References}

[1] DARROW, D.S., et al., Proc. of the 26th EPS Conf. on Controlled Fusion and Plasma Phys., Maastricht, 1999.

[2] YAVORSKIJ, Y.A., et al., to appear in Nucl. Fusion (2002).

[3] YAKOVENKO, Yu. V., et al., Proc. of 29th EPS Conf. on Controlled Fusion and Plasma Physics, Montreaux, 2002. ECA Vol. 26B (2002), paper O5.09

[4] WONG, K.-L., Plasma Phys. Cont. Fusion 41 (1999) R1.

[5] HEIDBRINK, W.W., et al., Nucl. Fusion 28 (1988) 1897.

[6] ONGENA, J., et al., Trans. Fusion Tech. 33 (1998) 181.

[7] GORELENKOV, N.N., CHENG, C.Z., Nucl. Fusion 35 (1995) 1743.

[8] FREDRICKSON, E.D., et al, Phys. of Plasmas 9 (2002) 2069.

[9] CHENG, C.Z., et al., these proceedings.

[10] FREDRICKSON, E.D., et al., Proc. of 29th EPS Conf. on Controlled Fusion and Plasma Physics, Montreaux, 2002, paper P-1.104. 


\section{External Distribution}

Plasma Research Laboratory, Australian National University, Australia

Professor I.R. Jones, Flinders University, Australia

Professor João Canalle, Instituto de Fisica DEQ/IF - UERJ, Brazil

Mr. Gerson O. Ludwig, Instituto Nacional de Pesquisas, Brazil

Dr. P.H. Sakanaka, Instituto Fisica, Brazil

The Librarian, Culham Laboratory, England

Library, R61, Rutherford Appleton Laboratory, England

Mrs. S.A. Hutchinson, JET Library, England

Professor M.N. Bussac, Ecole Polytechnique, France

Librarian, Max-Planck-Institut für Plasmaphysik, Germany

Jolan Moldvai, Reports Library, MTA KFKI-ATKI, Hungary

Dr. P. Kaw, Institute for Plasma Research, India

Ms. P.J. Pathak, Librarian, Insitute for Plasma Research, India

Ms. Clelia De Palo, Associazione EURATOM-ENEA, Italy

Dr. G. Grosso, Instituto di Fisica del Plasma, Italy

Librarian, Naka Fusion Research Establishment, JAERI, Japan

Library, Plasma Physics Laboratory, Kyoto University, Japan

Research Information Center, National Institute for Fusion Science, Japan

Dr. O. Mitarai, Kyushu Tokai University, Japan

Library, Academia Sinica, Institute of Plasma Physics, People's Republic of China

Shih-Tung Tsai, Institute of Physics, Chinese Academy of Sciences, People's Republic of China

Dr. S. Mirnov, TRINITI, Troitsk, Russian Federation, Russia

Dr. V.S. Strelkov, Kurchatov Institute, Russian Federation, Russia

Professor Peter Lukac, Katedra Fyziky Plazmy MFF UK, Mlynska dolina F-2, Komenskeho Univerzita, SK-842 15 Bratislava, Slovakia

Dr. G.S. Lee, Korea Basic Science Institute, South Korea

Mr. Dennis Bruggink, Fusion Library, University of Wisconsin, USA

Institute for Plasma Research, University of Maryland, USA

Librarian, Fusion Energy Division, Oak Ridge National Laboratory, USA

Librarian, Institute of Fusion Studies, University of Texas, USA

Librarian, Magnetic Fusion Program, Lawrence Livermore National Laboratory, USA

Library, General Atomics, USA

Plasma Physics Group, Fusion Energy Research Program, University of California at San Diego, USA

Plasma Physics Library, Columbia University, USA

Alkesh Punjabi, Center for Fusion Research and Training, Hampton University, USA

Dr. W.M. Stacey, Fusion Research Center, Georgia Institute of Technology, USA

Dr. John Willis, U.S. Department of Energy, Office of Fusion Energy Sciences, USA

Mr. Paul H. Wright, Indianapolis, Indiana, USA 
The Princeton Plasma Physics Laboratory is operated by Princeton University under contract with the U.S. Department of Energy.

\author{
Information Services \\ Princeton Plasma Physics Laboratory \\ P.O. Box 451 \\ Princeton, NJ 08543
}

Phone: 609-243-2750

Fax: 609-243-2751

e-mail: pppl_info@pppl.gov

Internet Address: http://www.pppl.gov 